\title{
ETNOTURISMO COMO MEIO DE PROMOÇÃO DO DESENVOLVIMENTO SUSTENTÁ VEL E VALORIZAÇÃO DA CULTURA DOS POVOS TRADICIONAIS DA AMAZÔNIA BRASILEIRA
}

\author{
Ridivan Clairefont de Souza Mello Neto ${ }^{1}$ \\ Marcela Augusto Toppino
}

\section{RESUMO:}

O trabalho objetiva analisar em que medida o etnoturismo social e ambientalmente responsável podem ser meios capazes de promover o desenvolvimento sustentável e a inclusão dos povos tradicionais da Amazônia sem degradação ambiental desnecessária e desarrazoada, valorizando costumes, religiosidades e modos de vida e considerando os integrantes dessas comunidades como atores principais nesse processo, que apenas pode ocorrer através da sua vontade objetivando a promoção de sua autonomia e liberdade para que não dependam exclusivamente de prestações positiva estatais. Dessa forma reconhece-se a sua identidade como parte da História do Brasil e do mundo e garante-se maior representatividade e proteção.

Palavras-chave: etnoturismo; povos e comunidades tradicionais; ecoturismo; desenvolvimento sustentável; diversidade

\section{ETNOTURISM AS AN INSTRUMENT TO PROMOTE SUSTAINABLE DEVELOPMENT AND VALORIZATION OF THE CULTURE OF TRADITIONAL PEOPLES OF THE BRAZILIAN AMAZON}

\begin{abstract}
:
The objective of this study is analyze the extent to which socially and environmentally responsible ethnotourism can be instrument capable of promoting the sustainable development and inclusion of the traditional Amazonian peoples without unnecessary and unreasonable environmental degradation, valuing customs, religiosities and ways of life, considering the members of communities as main actors in this process, which can occur through their will aiming at promoting their autonomy and freedom so that they don't rely exclusively on positive state benefits. So, their identity is recognized as part of the history of Brazil and the world, and it guarantees representativeness and protection.
\end{abstract}

Keywords: ethnotourism; traditional peoples and communities; ecotourism; sustainable development; diversity

\section{INTRODUÇÃO}

\footnotetext{
${ }^{1}$ Mestrando em Direito, Políticas Públicas e Desenvolvimento Regional no CESUPA-PA. Membro do Grupo de Pesquisa "Democracia, Poder Judiciário e Direitos Humanos". Advogado. E-mail: ridivan@hotmail.com.

2 Mestranda em Direito, Políticas Públicas e Desenvolvimento Regional no CESUPA-PA. Analista do Ministério Público do Estado do Pará. E-mail: marcelatoppino@gmail.com
} 
O presente trabalho visa verificar em que medida o etnoturismo social e ambientalmente responsável podem ser meios capazes de promover o desenvolvimento sustentável e a inclusão dos povos tradicionais da Amazônia e tem, como premissa, a ideia de que - para que a cultura e o meio ambiente dos povos tradicionais amazônicos (PTA) sejam preservados - faz-se necessário que os seus modos de vida sejam valorizados, sua cultura conhecida, seu meio ambiente respeitado e, principalmente, seus direitos humanos e fundamentais efetivados.

Trata-se de pesquisa científica básica, de abordagem qualitativa e caráter descritivo, realizada por meio do estudo de documentos e da bibliografia sobre o tema. Parte-se da ideia de que, em um mundo onde vigora o capitalismo e a globalização, para que esses PTA, sua cultura e espaço sejam respeitados e preservados, faz-se necessário que eles tenham meios econômicos de se prover e sustentar para que não dependam exclusivamente da promoção de políticas públicas direcionadas a sua manutenção.

É preciso, portanto, buscar o estabelecimento de meios que possibilitem a convivência harmoniosa entre a lógica de mercado e a proteção das comunidades tradicionais, bem como seus valores culturais e sociais. Em verdade, o principal desafio que se impõe é a necessidade de inserção dos povos tradicionais no dinamismo econômico, mas respeitando e valorizando suas tradições e identidade.

Propõe-se que estas comunidades utilizem suas próprias tradições e costumes para se desenvolver pautados numa lógica de desenvolvimento sustentável e respeito ao meio ambiente e da comunidade onde vivam. Sabe-se que o conceito de desenvolvimento sustentável é um conceito multidimensional que pressupõe várias frentes de atuação para ser concretizado e, diante disso, não se restringe apenas à noção de proteção ambiental. Ao contrário, pressupõe um conceito cultural, social, econômico e propriamente o ambiental.

Considerando esse panorama, o presente trabalho possui o objetivo geral de realizar estudo acerca de como a exploração do etnoturismo pelos PTA pode ser um dos meios para promover o seu desenvolvimento sustentável e a valorização de sua cultura e identidade. Neste sentido, como objetivo específico o presente trabalho busca verificar como esta visão de turismo sustentável, se feito com o cuidado e fiscalização necessários, pode promover a valorização da cultura desses povos e se tornar fonte de renda, sem ensejar nem aculturação, 
nem degradação ambiental, mas sim a valorização da diversidade cultural e a preservação do meio ambiente.

Além do mais, realiza-se uma análise crítica acerca do papel do Estado no desenvolvimento de políticas voltadas ao incentivo deste tipo de turismo, visto que muitas vezes a agenda governamental se volta ao desenvolvimento de políticas em locais onde já há estruturação turística econômica consolidada, tal como no eixo centro-sul, e deixa de lado locais como a Amazônia que, diante de sua complexidade, exige políticas específicas em respeito às comunidades tradicionais e suas características culturais, econômicas e culturais específicas.

\section{CONCEITOS DE DESENVOLVIMENTO SUSTENTÁVEL E POVOS TRADICIONAIS DA AMAZONIA}

O conceito de povos tradicionais utilizado no presente trabalho é o disposto no inciso I do art. $3^{\circ}$ do Decreto $n^{\circ} 6.040$ de 7 de Fevereiro de 2007, que institui a Política Nacional de Desenvolvimento Sustentável dos Povos e Comunidades Tradicionais (PNPCT) e os define como:

(...) grupos culturalmente diferenciados e que se reconhecem como tais, que possuem formas próprias de organização social, que ocupam e usam territórios e recursos naturais como condição para sua reprodução cultural, social, religiosa, ancestral e econômica, utilizando conhecimentos, inovações e práticas gerados e transmitidos pela tradição

$\mathrm{Na}$ Amazônia, esses povos/comunidades tradicionais consubstanciam-se principalmente nas populações ribeirinhas, índios e quilombolas que são detentores de uma cultura, religiosidade e modo de vida bastante diferenciados, praticam atividades econômicas de baixo impacto ambiental e necessitam da preservação de seu habitat para continuarem exercendo a liberdade de viver como seus ancestrais, se assim quiserem.

Considerando as peculiaridades dos PTA, o desenvolvimento de que se fala no presente trabalho é o sustentável, que abarca não apenas o crescimento econômico, mas a inclusão social dos mais pobres e a preservação do meio ambiente para as gerações futuras e presentes; nele vigora a solidariedade sincrônica com as gerações presentes e a anacrônica com as futuras, tendo como escopo a garantia de acesso aos bens da vida a todos, inclusive à maioria da população, que é pobre e a preservação do meio ambiente, sem olvidar que, para tanto, o crescimento econômico e a geração de renda são necessários (SACHS, 2009). 
O desenvolvimento sustentável visa à promoção da liberdade material dos indivíduos, que necessitam da inclusão no mercado para prover seu próprio sustento e se autodeterminar, sem se tornar totalmente dependentes de prestações positivas por parte do Estado (VEIGA, 2010). A promoção do desenvolvimento costuma, contudo, vir acompanhada de aculturação, substituição dos costumes dos povos tradicionais pelo modo de vida ocidental/eurocêntrico e até a perda de seu habitat.

A questão da democracia também se relaciona de perto a outro problema cultural que justificadamente tem recebido alguma atenção no presente. Tratase do poder esmagador da cultura e do estilo de vida ocidentais para solapar modos de vida e costumes tradicionais. Para todos que se preocupam com o valor da tradição e dos costumes culturais nativos, essa é uma ameaça realmente grave (SEM, 2010, p.308)

Michel Prieur (2014) afirma que a definição de desenvolvimento sustentável é multifacetada e exige que se adotem diversas frentes de atuação que se alcance um equilíbrio.

L'interdépendance et la complémentarité conséquence de l'intégration: le développement durable est celui qui prend en compte simultanément le développement économique, la protection de l'environnement, l'équité sociale et les valeurs culturelles. Ces quatre piliers du développment durable doivent être interdépendants et complémentaires selon la Déclaration de Johannesburg sur le développement durable de 2002 (...) La gouvernance: le développement durable exige un nouveau mode de gestion publique et privée qui impose la transparence et la participation de tous les acteurs (PRIEUR, 2014, p.20) ${ }^{3}$

Para que os PTA possam ser incluídos social e economicamente sem deixar seu modo de vida tradicional e cultural é necessário que se encontre uma forma de os conformar às leis do mercado, mas sem fazer com que esses povos tenham apenas duas opções: abrir mão de sua cultura, lugar e modo de vida ou viver na pobreza e manter seus costumes e tradições pelo tempo que conseguirem.

E é exatamente aí que o etnoturismo voltado para os PTA apresenta-se como um dos meios para transformar a cultura, modo de vida e ambiente dos povos tradicionais em algo economicamente rentável e valorizado, possibilitando tanto a veiculação de suas culturas, quanto a sua manutenção sem que eles precisem escolher entre o modo de vida tradicional e o acesso aos bens da vida.

\footnotetext{
${ }^{3}$ Tradução: "A Interdependência e complementaridade como consequência da integração: O desenvolvimento sustentável é aquele que simultaneamente leva em conta o desenvolvimento econômico, a proteção ambiental, a eqüidade social e os valores culturais. Esses quatro pilares do desenvolvimento sustentável devem ser interdependentes e complementares, de acordo com a Declaração de Joanesburgo sobre Desenvolvimento Sustentável de 2002 (...) Governança: o desenvolvimento sustentável exige um novo modo de gestão pública e privada que exija transparência e participação dos países todos os atores"
} 
Essa ideia parte da premissa de que as políticas públicas ambientais precisam incluir os povos tradicionais, promovendo o sociodesenvolvimento e a melhoria das condições de vida dessa população, a fim de que se realize uma justa repartição dos benefícios da exploração dos recursos ambientais. (SANTILLI, 2005).

Demanda-se, neste sentido, uma reformulação das políticas públicas e modificação do comportamento estatal no sentido de compreender os povos tradicionais como protagonistas de seu desenvolvimento através da proteção de sua própria cultural e tradições.

\section{ETNOTURISMO, DESENVOLVIMENTO SUSTENTÁVEL E MEIO AMBIENTE}

O turismo, como costuma ser explorado, promove grande degradação ambiental, aculturação e costuma retirar a população local do lugar onde vive, por que, com o crescimento econômico da região explorada, ela passa a se tornar um local de custo de vida demasiadamente caro e a pressão pela ocupação de seu território acaba por "expulsar" os antigos moradores.

Esses efeitos são causados pela exploração do turismo de massa, sem responsabilidade ambiental e social e que visa à exploração dos recursos do local para obter apenas lucro e não à promoção do desenvolvimento local, do meio ambiente e da cultura dos povos tradicionais (ARAÚJO, 2017).

Não é essa a noção de turismo apresentada como alternativa para a promoção do desenvolvimento sustentável dos povos tradicionais. Um etnoturismo/ecoturismo responsável, bem regulamentado e fiscalizado, em que as populações tradicionais sejam valorizadas, sua cultura reconhecida e elas próprias decidam como ele se dará e até que ponto desejam o explorar é o que se propõe.

Para o etnoturismo, o saber, a cultura tradicional e o meio ambiente pouco alterado não são vistos como empecilho, mas como atração principal. Busca-se trazer visibilidade para os povos tradicionais, valorizar sua identidade e história, entendendo que é preciso conhecer para proteger. Busca-se, portanto, um desenvolvimento sustentável que busca equilibrar a proteção dos ecossistemas e a sustentabilidade local, onde o turista convive com a identidade local, conhece e, ao mesmo tempo a respeita (ARAÚJO, 2017).

Esse entendimento está de acordo com o disposto no caput do art.180 da Constituição Federal (BRASIL, 1988): “A União, os Estados, o Distrito Federal e os Municípios promoverão e incentivarão o turismo como fator de desenvolvimento social e econômico". A 
importância do turismo, como propulsor do desenvolvimento socioeconômico, é, portanto, constitucionalmente reconhecida e a sua promoção tratada como objetivo a ser concretizado.

Nesse mesmo sentido e respeitando a autonomia dos indígenas, o Decreto $\mathrm{n}^{\mathrm{o}} 7.747 \mathrm{de}$ 5 de Junho de 2012, que institui a Política Nacional de Gestão Territorial e Ambiental de Terras Indígenas (PNGATI) define como um de seus objetivos

Apoiar iniciativas indígenas sustentáveis de etnoturismo e de ecoturismo, respeitada a decisão da comunidade e a diversidade dos povos indígenas, promovendo-se, quando couber, estudos prévios, diagnósticos de impactos socioambientais e a capacitação das comunidades indígenas para a gestão dessas atividades (BRASIL, 2012)

A legislação constitucional e infraconstitucional brasileira reconhecem a importância do turismo como forma de promoção do desenvolvimento sustentável, tanto local, como nacional e garante aos povos tradicionais o poder decisório no que tange à implementação e gestão desse turismo socioambentalmente sustentável; garantindo, ainda, a capacitação dessas comunidades tradicionais para realizar essa gestão. Tudo com o fim de que garantir sua autonomia, a valorização de sua identidade e que o lucro decorrente do turismo seja aproveitado pela própria comunidade tradicional.

A legislação internacional sobre o turismo também está em consonância com os ditames desse etnoturismo sustentável, como se pode depreender a partir da leitura de diversos artigos do Código de Ética Mundial para Turismo (CEMT), norma por meio da qual a Organização Mundial de Turismo (OMT) - entidade vinculada à Organização das Nações Unidas (ONU) - proclamou os princípios éticos do turismo internacional, conferindo especial relevância à promoção do desenvolvimento sustentável e da valorização da diversidade como finalidades da atividade turística, como se pode perceber a partir da leitura do artigo $3^{0^{4}}$ do referido documento (OMT, 1999).

4 O TURISMO, FATOR DE DESENVOLVIMENTO SUSTENTÁVEL 1. Todos os agentes de desenvolvimento turístico têm o dever de proteger o meio ambiente e os recursos naturais, com vistas a um crescimento econômico estruturado, constante e sustentável, que seja capaz de satisfazer equitativamente as necessidades e aspirações das gerações presentes e futuras. 2. As autoridades públicas nacionais, regionais e locais favorecerão e incentivarão todas as modalidades de desenvolvimento turístico que permitam preservar recursos naturais escassos e valiosos, em particular a água e a energia, e evitar no que for possível a produção de resíduos. 3. Serão feitos esforços para distribuir no tempo e no espaço os movimentos de turistas e visitantes, em particular por meio das férias remuneradas e das férias escolares, e equilibrar melhor o fluxo turístico, com o objetivo de reduzir a pressão causada pela atividade turística no meio ambiente e de aumentar seus efeitos benéficos no setor turístico e na economia local. 4. A infraestrutura e as atividades turísticas serão planejadas de modo a proteger o patrimônio natural que constituem os ecossistemas e a diversidade biológica e a preservar as espécies da fauna e da flora silvestre em perigo. Os agentes do desenvolvimento turístico, e em particular os profissionais do setor, devem admitir que se imponham limites a suas atividades quando exercidas em espaços particularmente vulneráveis: regiões desérticas, polares ou de montanha, litorâneas, florestas tropicais ou zonas 
Existe, portanto, um arcabouço normativo, nacional e internacional, que entende o turismo ético e responsável como atividade capaz de, associada a outros incentivos e políticas públicas, impactar positivamente as comunidades receptoras, promovendo o sociodesenvolvimento sustentável da região.

O etnoturismo socioambientalmente sustentável promoveria a afirmação de um poder endógeno das comunidades tradicionais, que passariam a dispor meios e recursos para se autogerir, apropriando-se dos recursos financeiros da exploração turística ambientalmente correta de seu território e de seu patrimônio cultural (material e imaterial). O etnoturismo, possibilitaria, portanto, que os integrantes dos PTA participassem ativamente do processo de desenvolvimento de sua comunidade, garantindo que os frutos de sua exploração se revertam em melhoria da qualidade vida desses povos tradicionais (CRUZ, 2008).

\section{ETNOTURISMO E A DEMANDA POR NOVAS EXPERIÊNCIAS}

O turismo vem passando por mudanças significativas, mas ao mesmo tempo contraditórias. À medida que a globalização, integração e homogeneização de costumes cresce em razão do intercambio cultural, os turistas passam a procurar por algo diferente, costumes e culturas diversas da dominante. E é nesse contexto que o etnoturismo e o turismo comunitário ganham força.

Mudanças significativas vêm ocorrendo na motivação dos turistas internacionais para viajar, que teriam como razões principais para realizar esse deslocamento: conhecer outras culturas, conhecer novos estilos de vida e lugares de beleza natural (SANSOLO e BURSZTYN, 2008). Essa mudança de paradigma nas intenções/motivações turísticas criam uma grande oportunidade para os povos em comunidades tradicionais da Amazônia, uma vez que a região é detentora de diversidade biológica incomparável com a de qualquer lugar do mundo, belezas naturais consideráveis e um patrimônio cultural, material e imaterial, que apesar de bastante grande, ainda é muito pouco explorado.

Esse tipo de turismo contribui para uma troca de saberes, que não se limita a visualização de uma comunidade considerada exótica e de baixa renda por pessoas de fora, mas ultrapassa esses conceitos para dar lugar a um sentimento de pertencimento, trocas de

úmidas, que sejam idôneos para a criação de parques ou reservas protegidas. 5. O turismo de natureza e o ecoturismo são reconhecidos como formas de turismo particularmente enriquecedoras e valorizadoras, sempre que respeitem o patrimônio natural e a população local e se ajustem à capacidade de carga dos lugares turísticos 
conhecimentos, com respeito e abertura suficientes para promover o compartilhamento de experiências que os turistas tanto buscam, uma vez que "O lugar turístico é o palco da pluralidade de identidades e o cenário da trama complexa das relações sociais" (IRVING, 2003, p. 177-178). O CEMT corrobora esse entendimento ao dispor em ser art. $2^{\circ}$, que o turismo é instrumento de desenvolvimento pessoal e coletivo (OMT, 1999) ${ }^{5}$

Transita-se de uma ideia de que o meio ambiente e as comunidades tradicionais são meros expectadores do desenvolvimento que são subjugados à lógica de mercado para uma visão pautada na sua inclusão, sempre levando em consideração suas peculiaridades e características específicas que os tornam especiais e valorosos para o próprio incentivo ao etnoturismo.

Diferente do que ocorre com o turismo de massa, em que o local turístico é alterado significativamente para atender aos anseios do turista; no etnoturismo e/ou turismo comunitário, a preocupação é outra: mostrar a verdade da comunidade de forma socioambientalmente responsável e proporcionar uma experiência de aprendizado com o diferente, respeitando as diversidades sociais e biológicas do local e tendo sempre os interesses das comunidades locais como finalidades a serem perseguidas.

Nesse sentido, a alteração significativa do local para agradar turistas não faz sentido. Ao contrário, faz-se necessária a escolha consciente do turista que entrará no local, tanto no que concerne às intenções dos turistas, que devem estar plenamente informados acerca das peculiaridades do local, quanto da quantidade dos mesmos, pois a abertura demasiada acaba por dificultar o controle dos impactos ambientais e socioculturais da atividade (IRVING, 2008).

\section{POTENCIAL PARA O ETNOTURISMO SUSTENTÁ VEL POUCO EXPLORADO NA AMAZÔNIA E EM SUAS COMUNIDADES TRADICIONAIS}

Apesar da expansão pela procura do etnoturismo sustentável - que visa à promoção do encontro de culturas diversas e o desenvolvimento das comunidades receptoras sem promover a aculturação, nem a degradação ambiental no território dos povos tradicionais - e do grande

\footnotetext{
${ }^{5}$ O TURISMO, INSTRUMENTO DE DESENVOLVIMENTO PESSOAL E COLETIVO 1. O turismo, que é uma atividade geralmente associada ao descanso, à diversão, ao esporte e ao acesso à cultura e à natureza, deve ser entendido e praticado como um meio privilegiado de desenvolvimento individual e coletivo. Quando vivenciado com a abertura de espírito necessária, é um fator insubstituível de autoeducação, tolerância mútua e aprendizagem das legítimas diferenças entre povos, culturas e sua diversidade. (...)
} 
potencial da Amazônia brasileira para sua exploração, verifica-se que o etnoturismo não tem recebido grande atenção na região.

A Amazônia brasileira povoa o imaginário social mundial e desperta a curiosidade de estrangeiros e brasileiros, que não conhecem a maior floresta tropical do mundo e desejam conhecer os povos da floresta (em especial, ribeirinhos, índios e quilombolas), seu habitat, cultura, religiosidade, culinária e modos de vida. A Amazônia brasileira detém, portanto, diversidade social e biológica incomparáveis, mas delas não usufrui, mantendo as comunidades tradicionais isoladas e desconhecidas.

As políticas públicas voltadas para essas comunidades tradicionais, quando existem, costumam se manifestar no sentido de promover a proteção pelo isolamento e não pela valorização da diversidade, desconsiderando que o encontro intercultural e até o acesso a novas tecnologias por essas comunidades não aniquilará sua cultura se feito com o cuidado devido, mas talvez seja capaz de reafirmá-la em âmbito nacional e internacional, fazendo com que - por meio do reconhecimento dessa identidade e da história desses povos - a proteção a eles conferida torne-se ainda maior e sua participação nos processos decisórios acerca de seu destino seja mais significativa, pois essas populações teriam um considerável acréscimo de recursos, deixando gradativamente de depender quase exclusivamente da atuação governamental.

Entende-se que o ecoturismo pressupõe a garantia de acesso das populações tradicionais às inovações técnicas. Deve-se, neste sentido, possibilitar que a cultura seja vista como um meio de aprendizagem entre homem e meio. Transita-se de uma visão de que o meio ambiente tradicional deva ser visto apenas como um museu e passa-se a encará-lo como uma comunidade dinâmica que se utilize da atividade econômica e de outras técnicas para a preservação de sua cultura e valores (TAVARES, 2008).

A criação, implementação e fiscalização de políticas públicas promotoras do etnoturismo voltado para o conhecimento, valorização e respeito das comunidades tradicionais e seu território é necessária hoje para que as identidades desses povos sejam reafirmadas, seus direitos respeitados e eles possam alcançar um desenvolvimento que se coadune com suas culturas e modos de vida.

Há um processo de transição e modificação comportamental tanto da iniciativa privada quanto de organizações governamentais no modo de encarar a prática turística em comunidades tradicionais. O desenvolvimento de um turismo sustentável passou a ser visto 
com bons olhos perante o mercado e os próprios consumidores. O turismo passou a ser encarado a partir de uma nova perspectiva e tornou-se pauta a partir de sua relação com práticas sociais e ambientais, efetividade de direitos e preservação de valores e identidade das comunidades (IRVING, 2008).

Contudo, enquanto essas políticas públicas não são implementadas, as comunidades tradicionais permanecem sem grande visibilidade e sofrendo com o descaso do poder público, enquanto poderiam estar atuando como agentes promotores de seu próprio desenvolvimento e mostrando para o mundo o valor de sua cultura, modo de vida e habitat.

Além disso, é preciso que o poder público encare o desenvolvimento deste tipo de política como um investimento a longo prazo. A possibilidade de uma comunidade atuar na promoção de sua identidade e obter retorno financeiro com isto e preservar sua identidade e cultura permite que cada vez mais este grupo de pessoas passe a se tornar independente do aparato estatal.

Diante desta falta de efetividade das políticas públicas o que se tem são comunidades que ficam à margem da possibilidade de um desenvolvimento sustentável, não participando da lógica turística e, por consequência, não tendo a possibilidade de instrumentalizar mecanismos que efetivem a afirmação de sua identidade e valores, bem como garantam o seu desenvolvimento econômico autônomo (TAVARES, 2008).

Considerando a necessidade de investir no setor, foi criado o Programa de Desenvolvimento do Ecoturismo para a Amazônia Legal (PROECOTUR) na década de 90 oriundo de um consórcio entre Ministério do Meio Ambiente (MMA) e o Instituto Brasileiro de Turismo (EMBRATUR), que teria suas ações financiadas pelo Banco Interamericano de Desenvolvimento (BID); esse programa tem como escopo promover o ecoturismo no Brasil e confere especial importância ao turismo sustentável na Amazônia Legal (PINTO, 2007).

Contudo, como não é incomoum acontecer no Brasil, o Projeto ainda não saiu da primeira fase e alcançou resultados bem mais modestos do que se esperava. Outro fator que demonstra o baixo interesse governamental na promoção do etnoturismo na região amazônica brasileira é o envio de poucos projetos relacionados à promoção do turismo comunitário da região para a $2^{\mathrm{a}}$ Edição do Plano Nacional do Turismo - Uma Viagem de Inclusão, 20072010 promovido pelo MMA.

Trata-se de Plano de incentivo para o etnoturismo inclusivo, por meio do qual liberavam-se recursos para a promoção do turismo comunitário e - a pesar do grande 
potencial da Amazônia para explorar essa modalidade de turismo - as regiões Sul, Sudeste e Nordeste foram responsáveis pelo envio de $80 \%$ dos projetos, enquanto a região Norte, onde fica a maior parte da Amazônia brasileira foi a que enviou menos projetos, sendo responsável por apenas 9\% do envio (SILVA, RAMIRO e TEIXEIRA, 2008).

Os Estados que mais enviaram projetos para receber verbas para a promoção desse etnoturismo sustentável foram: Minas Gerais, São Paulo, Paraná, Rio de Janeiro, Rio Grande do Sul e Bahia (nenhum integrante da Amazônia Legal), enquanto Pará, Mato Grosso e Amazonas, todos Estados integrantes da Amazônia Legal, ficaram respectivamente em $11^{\circ}$, $12^{\circ}$ e $14^{\circ}$ lugar no ranking de envio de projetos de etnoturismo, o que evidencia o descaso com o potencial turístico da região (SILVA, RAMIRO e TEIXEIRA, 2008).

Evidencia-se aqui um grave problema de política pública, visto que os recursos passaram a ser direcionados de forma equivocada ou fora de contexto. $\mathrm{O}$ desenvolvimento de projetos voltados ao turismo sustentável deveria ter tido como foco principal a Amazônia e sua rica identidade cultural e ambiental. Entretanto, os recursos foram destinados em sua maioria ao eixo centro-sul onde a estrutura cultural e econômica é muito mais consolidada.

Necessário, portanto, que se reformulem as políticas públicas voltadas ao etnoturismo, com vistas a permitir um melhor aproveitamento dos recursos e a concretização de projetos que efetivamente permitam o alcance do desenvolvimento de um turismo ecológico e equilibrado.

Apesar de não haver grandes incentivos para a promoção do etnoturismo ambiental e socialmente sustentável na Amazônia (ou a instrumentalização errônea das políticas e recursos) e, em especial, nas comunidades tradicionais que a habitam, a demanda pelo conhecimento da região e a necessidade dessas comunidades tanto de gerar/auferir renda como de serem vistas pelo resto do mundo, com ele interagir e por ele ser conhecida e reconhecida, fez com que uma interessante iniciativa ocorrida no município de Silves no Amazonas prosperasse.

A maior parte da população do referido município é composta por ribeirinhos que retiravam seu sustento da pesca, mas que viram o ambiente em que viviam ameaçado pela pesca predatória. A comunidade ribeirinha residente no local, com o auxílio de setores progressistas da Igreja Católica, formou a Associação de Silves para a Preservação Ambiental e Cultural (ASPAC) em 1993. Já em 1994, essa associação recebeu verbas do governo da Áustria e da Organização Não Governamental (ONG) WWF-Brasil, para construir um "hotel 
selva": a Pousada Aldeia dos Lagos, que passou a ser gerida pela comunidade local, que foi capacitada para trabalhar com o turismo e aufere proveito econômico da exploração turística da região (CRUZ, 2008).

Este é um exemplo interessante de como o ecoturismo pode passar a ser a principal fonte de renda da comunidade que não pratica mais a pesca predatória e que assumiu o protagonismo na exploração sustentável dos recursos naturais da região, reafirmando valores e sua própria identidade através da geração de renda e da preservação cultural (CRUZ, 2008).

\section{CONCLUSÃO}

A partir da pesquisa apresentada, pode-se concluir que o etnoturismo social e ambientalmente responsável se revela como uma das formas de promover o desenvolvimento sustentável das comunidades e povos tradicionais da Amazônia. Na perspectiva desse tipo de exploração da atividade turística, os povos da floresta, seu habitat e cultura são valorizados, reconhecendo-se o seu valor e promovendo a troca de saberes e experiências entre turistas e comunidade recebedora.

Não se imagina que o etnoturismo seja suficiente para resolver todos os problemas socioambientais das comunidades tradicionais da Amazônia brasileira, mas que pode desempenhar papel substancial na promoção de um desenvolvimento mais inclusivo e humanizado e que entenda os integrantes dessas comunidades como protagonistas de seu próprio desenvolvimento, detentores de autonomia e sujeitos de sua própria história e não como objetos de uma exploração turística e/ou agropecuária predatória, conforme determinado pela OMT.

Contudo, verificou-se, também que - apesar do grande potencial para a realização do etnoturismo pelas comunidades tradicionais da Amazônia, do crescente interesse por essa forma de fazer turismo e de estar conforme a legislação nacional e internacional sobre o assunto deve-se destacar que não são realizadas políticas públicas suficientes para promover o seu desenvolvimento. O problema, como costuma ser no Brasil, não é a norma defasada e/ou pouco garantidora de direitos, mas a sua inefetividade.

O desafio passa a ser, portanto, não tanto a previsão legal buscando desenvolvimento sustentável ou um turismo equilibrado, pois tal previsão já consta da própria Constituição Federal. Ao contrário, o desafio que se impõe na atualidade brasileira é a efetividade da 
norma legal, ou seja, garantir que se criem políticas públicas efetivas e que isto se torne uma política de Estado e não de governo (BOBBIO, 1992).

O direito à promoção de políticas públicas voltadas ao fortalecimento do turismo comunitário, inclusivo e ambientalmente responsável existe e são realizadas políticas públicas (ainda que poucas) no Brasil nesse sentido. Entretanto, na Amazônia brasileira, que goza de socio/biodiversidade impressionantes, essas políticas públicas mostram-se incipientes e as comunidades tradicionais permanecem, em regra, alijadas do desenvolvimento usufruído pelo restante do país, dependendo de políticas públicas que - a pretexto de as proteger e ao meio ambiente em que vivem - promovem o seu isolamento, fazendo com que a sua cultura seja gradualmente desvalorizada e desconsiderada como parte integrante da cultura e identidade nacionais.

Necessário se faz que o governo, ao estabelecer políticas públicas para regiões como a Amazônia, entenda as peculiaridades e especificidades locais, tais como o fato de que as comunidades tradicionais vivem um conflito diante da necessidade de buscar sua subsistência através de uma atividade econômica e o desejo de preservar sua identidade cultural e o meio ambiente onde vivem.

É neste sentido que práticas como o etnoturismo podem ser instrumentos que potencializam o respeito ao meio ambiente, forneçam um meio de sustento e garantam a proteção da cultura e valores das comunidades tradicionais sem a necessidade de degradar o meio ambiente ou descaracterizar o modo de vida das comunidades ali presentes.

Entretanto, é preciso que o Estado deixe de adotar políticas para locais onde já há uma estrutura turística e econômica bem desenvolvida como o eixo centro-sul do país e busque incentivar a adoção de medidas em locais mais precários neste sentido como a Amazônia. Além do mais, este tipo de visão deve transitar de uma mera agenda política para uma política de Estado, visto que a própria Constituição Federal exige a efetividade do desenvolvimento sustentável.

Diante disso, é preciso que se supere esta visão sobre a Amazônia e se entenda pela plena possibilidade conciliação entre desenvolvimento econômico, proteção ambiental e respeito à cultura e identidade das comunidades tradicionais. Em verdade, a própria noção de desenvolvimento sustentável demanda este tipo de comportamento.

A partir de seu aspecto multidensional entende-se por desenvolvimento sustentável uma integração entre desenvolvimento econômico, social, cultural e ambiental. Neste sentido, 
é preciso que se encare a Amazônia não como um local intocável que não possui potencial econômico, mas sim como um local que demanda políticas específicas que garantam a proteção ambiental e a sustentabilidade financeira e cultural das comunidades que ali vivem. O etnoturismo é, portanto, o futuro da Amazônia.

\section{REFERÊNCIAS}

ARAUJO, Wilson Alves de et al. Desenvolvimento local, turismo e populações tradicionais: elementos conceituais e apontamentos para reflexão. Interações (Campo Grande), Campo Grande , v. 18, n. 4, p. 5-18, Dec. 2017 . Disponível em: . Acesso em on 20/12/2018. http://dx.doi.org/10.20435/inter.v18i4.1392.

BOBBIO, Norberto. A era dos direitos/ Norberto Bobbio: tradução de Carlos Nelson Coutinho. - Rio de Janeiro: Campus, 1992. BRASIL. Constituição da República Federativa do Brasil de $1988 . \quad$ Disponível em: http://www.planalto.gov.br/ccivil_03/Constituicao/ConstituicaoCompilado.htm. Acesso em:20/12/2018

BRASIL. Decreto n⿳ 6.040 de 7 de Fevereiro de 2007. Disponível em: Erro! A referência de hiperlink não é válida.. Acesso em:20/12/2018.

BRASIL. Decreto N 7.747 de 5 de Junho de 2012. Disponível em: http://www.planalto .gov.br/ccivil_03/_ato2011-2014/2012/decreto/d7747.htm. Acesso em:20/12/2018.

CRUZ, Rita de Cássia Ariza. Turismo, produção do espaço e desenvolvimento desigual: para pensar a realidade brasileira. Disponível em: Erro! A referência de hiperlink não é válida.es/defaul t/turismo/o_ministerio/publicacoes/downloads_publicacoes/TURISMO_DE _BASE_COMUNITxRIA.pdf. Acesso em: 20/12/2018

IRVING, Marta de Azevedo. Reinventando a reflexão sobre turismo de base comunitária. Disponível em: http://www.turismo.gov.br/sites/default/turismo/o_ministeri o/publicacoes/downloads_pu blicacoes/TURISMO_DE _BASE_COMUNITxRIA.pdf. Acesso em: 20/12/2018

IRVING, Marta de Azevedo. Turismo como instrumento para desenvolvimento local: entre a potencialidade e a utopia. In: D'ÁVILA, M. I.; PEDRO, R. (Orgs.). Tecendo o Desenvolvimento: Saberes, Ética e Ecologia Social. Rio de Janeiro, 2003, p. 167-184

MMA. Principais resultados obtidos na fase I do PROECOTUR na Amazônia. Disponível em: http://www.mma.gov.br/desenvolvimento-rural/turismosustentável/desenvolviment o-ambiental-do-turismo/resultados.html. Acesso em 21/12/2018. 
OMT. Código de Ética Mundial para o Turismo. Disponível em: http://www.turismo.gov.b r/sites/default/turismo/o_ministerio/publica coes/downloads_p ublicacoes/PREVIEW_MT UR_Codigo_de_Etica_Turismo_120_210mm_Portugues.pdf. Acesso em 21/12/2018.

PINTO, Paulo Moreira. Políticas de turismo e sustentabilidade em comunidades tradicionais: perspectivas conceituais. Bol. Mus. Para. Emílio Goeldi. Ciênc. hum., Belém , v. 2, n. 1, p. 11-22, Apr. 2007 . Disponível em: from<http://www.scielo.br/scielo.php?script=sci_arttext\&pid=S198181222007000100002\&ln $\mathrm{g}=\mathrm{en} \& \mathrm{nrm}=\mathrm{iso}>$. Acesso em 21/12/2018. http://dx.doi.org/10.1590/S1981$\underline{81222007000100002 .}$.

PRIEUR, Michel. Droit de l'environnement, droit durable. Bruxelas: Éditions Bruylant, 2014.

SACHS, Ignacy. Proteção internacional do meio ambiente / organizadores: Marcelo D. Varella;e Ana Flavia Barros-Platiau. Brasília: Unitar, UniCEUB e UnB, 2009.

SANSOlO, D. G.; BURSZTYN, I. Turismo de Base Comunitária. Disponível em: http://www.turismo.gov.br/sites/default/turismo/o_ministerio/publicacoes/downloads_p ub licacoes/TURISMO_DE_BASE_COMUNITxRIA.pdf. Acesso em: 20/12/2018.

SANTILLI, Juliana. Socioambientalismo e Novos Direitos: proteção jurídica à diversidade biológica e cultural. Editora Petrópolis, 2005.

SILVA, K. T.P.; RAMIRO, R.C.; TEIXEIRA, B. S. Fomento ao turismo de base comunitária: a experiência do Ministério do Turismo. Disponível em: Erro! A referência de hiperlink não válida..turismo.gov.br/sites/default/turismo/o_ministerio/publicacoes/downloads_publicacoes/ TURISMO_DE_BASE_COMUNITxRIA.pdf. Acesso em: 20/12/2018.

TAVARES. Maria Gorete Tavares. Turismo e Desenvolvimento na Amazônia Brasileira: algumas considerações sobre o arquipélogo do Marajó - Pará. Disponível em: http://www.turismo.gov.br/sites/default/turismo/o_ministerio/publicacoes/downloads_publica coes/TURISMO_DE_BASE_COMUNITxRIA.pdf. Acesso em: 20/12/2018.

VEIGA, José Eli da. Desenvolvimento Sustentável: Desafio do Século XXI/José Eli da Veiga; Rio de Janeiro: Editora Garamond, 2010. 